Letters to the Editor

\title{
Selective Vaporization in Laser Ablation Solid Sampling for Inductively Coupled Plasma Atomic Emission and Mass Spectrometry of Steels
}

\author{
Tadashi Mochizuki, Akiko Sakashita, Takeshi Tsuj, Hideo Iwata, Yoichi Ishibashi and \\ Naoki GuNJ
}

Analysis Research Department, Advanced Technology Research Center, NKK Corporation, Minamiwatarida, Kawasaki 210, Japan

\begin{abstract}
Keywords Laser ablation, solid sampling, Q-switched ruby laser, Q-switched cw Nd:YAG laser, pulse Nd:YAG laser, steel analysis
\end{abstract}

A laser ablation technique has been studied as a versatile method of direct solid sampling for subsequent elemental analysis. It has been successfully coupled with analytical techniques such as atomic absorption spectrometry (AAS) ${ }^{1-3}$, microwave-induced ${ }^{4}$, direct current $^{5}$, and inductively coupled ${ }^{6,7}$ plasma atomic emission spectrometry (MIP-, DCP- and ICP-AES) and inductively coupled plasma mass spectrometry (ICP-MS)..$^{8-10}$ These tandem methods have a number of advantages such as high sensitivity, little or no sample preparation, small amount of samples required and the ability to analyze both conductive and nonconductive solids.

We recently investigated laser ablation/ICP-AES and ICP-MS in order to develop a rapid method for solid analysis. $7,8,11,12$ In these reports we showed that fractional vaporization, which limited analytical precision and accuracy, occurred during the ablation process. On the other hand, Hager ${ }^{10}$ indicated in a report on laser ablation/ICP-MS that differences in the response factors were observed between free-running and Q-switched laser modes of operation and that more uniform responses were obtained with the Q-switching mode. Thompson et al. ${ }^{13}$ also showed that the matrix effect associated with an ablation event can be minimized with a maximum Q-switched laser. These results show that the magnitude of selective vaporization depends on the types of laser pulses.

The present work aimed at investigating the laser dependence of selective vaporization. The use of six types of the laser pulses (three types of lasers each at two different running modes) was compared by collecting ablated particles, followed by analyzing them with solution-based ICP-AES or ICP-MS.

\section{Experimental}

Apparatus and operating conditions

The operating conditions of the three types of lasers are shown in Table 1, together with the amounts of ablated

Table 1 Laser operating conditions

\begin{tabular}{|c|c|c|c|c|c|c|}
\hline \multirow[b]{2}{*}{$\begin{array}{l}\text { Properties of } \\
\text { Q-switch }\end{array}$} & \multicolumn{2}{|c|}{$\begin{array}{c}\text { Ruby } \\
\text { (Cyanine dye cell) }\end{array}$} & \multicolumn{2}{|c|}{$\begin{array}{c}\text { cw Nd:YAG } \\
\text { (Acoustd optic Q-switch device) }\end{array}$} & \multicolumn{2}{|c|}{$\begin{array}{l}\text { Pulse Nd:YAG } \\
\text { (Pockels cell) }\end{array}$} \\
\hline & $\begin{array}{c}\text { Low } \\
\text { Q-switching }\end{array}$ & $\begin{array}{c}\text { High } \\
\text { Q-switching }\end{array}$ & $\begin{array}{c}\text { Moderate } \\
\text { Q-switching }\end{array}$ & $\begin{array}{c}\text { High } \\
\text { Q-switching }\end{array}$ & $\begin{array}{c}\text { Free- } \\
\text { running }\end{array}$ & Q-switching \\
\hline $\begin{array}{l}\text { Pulse repetition } \\
\text { rate }(\mathrm{Hz})\end{array}$ & 0.1 & 0.1 & 5000 & 1000 & 10 & 10 \\
\hline Maximum energy (J) & 1 & 0.1 & 0.010 & 0.016 & 0.75 & 0.35 \\
\hline $\begin{array}{l}\text { Half-width of } \\
\text { pulses (ns) }\end{array}$ & $1000^{a}$ & 50 & 160 & 110 & 2000 & 15 \\
\hline Peak power (MW) & 0.01 & 2 & 0.06 & 0.15 & 0.38 & 23 \\
\hline Ablation time (min) & 5 & 12 & 2 & 2 & 2 & 3 \\
\hline $\begin{array}{l}\text { Number of laser } \\
\text { shots (time) }\end{array}$ & 30 & 70 & $6.0 \times 10^{5}$ & $1.2 \times 10^{5}$ & 1200 & 1800 \\
\hline $\begin{array}{l}\text { Maximum amount of } \\
\text { particles }\left(\mu \mathrm{g} \mathrm{s}^{-1}\right)\end{array}$ & 0.14 & 0.002 & 22 & 12 & 2.9 & 0.13 \\
\hline
\end{tabular}

a. Half-width of spikes. Each pulse consists of about 250 spikes. 
particles. A cw Nd:YAG laser (Model SL115G/ SL231H/SL213C, NEC, Tokyo) was used in the Qswitched mode; and the laser pulses were fired at a pulserepetition rate of $5 \mathrm{kHz}$ or $1 \mathrm{kHz}$. A pulse Nd:YAG laser (Model SL402, Spectron Laser Systems Ltd., UK) was operated with or without Q-switching. The sample chamber and three-axis translation stage used for ablation with the YAG lasers were the same as previously described. ${ }^{7}$ The sample was horizontally moved at a speed of $10 \mathrm{~mm} \mathrm{~min}^{-1}$ in order to keep the focus on the sample surface. A ruby laser (for Laser Microanalyzer LMA-10, Carl Zeiss, Jena) and cylindrical sample chamber were the same as those described previously. ${ }^{8}$ The laser was operated with its lowest or highest degree of Q-switching, and each successive shot was fired on a fresh sample surface.

A schematic diagram of the particle collector is shown in Fig. 1. A membrane filter, supported on a glass holder, was connected to the exit of the ablation chamber with Tygon tubing (length $1 \mathrm{~m}$, i.d. $4 \mathrm{~mm}$ ). The filter used was a cellulose nitrate film with $0.2 \mu \mathrm{m}$ diameter holes (Cat. No. A020A025A, Toyo Roshi Kaisha; Ltd.). The ablated material was swept out of the chamber by a flowing argon carrier gas (flow rate $0.81 \mathrm{~min}^{-1}$ ). At the exit of the collector the argon flow was pumped out by means of a diaphragm vacuum pump (pumping capacity $151 \mathrm{~min}^{-1}$ ) in order to prevent the inner pressure of the chamber from increasing.

\section{Samples and reagents}

The types of steel used for the investigation were JSS (Japanese Industrial Standards of Iron and Steel) standard reference materials. The JSS standards were as follows: carbon steel (JSS 164-4); low-alloy steel (JSS 15110 and 153-10); stainless steel (JSS650-5, 654-5 and 6555); and high-speed steel (JSS607-8 and 609-8).

All of the chemicals used were of analytical reagent grade, unless otherwise mentioned.

\section{Procedure}

The steel disc was set in the laser ablation chamber and the laser focussed on the sample surface. Particles ablated by laser shots were introduced into a particle collector by a flowing argon carrier gas, and collected on a $0.2 \mu \mathrm{m}$ membrane filter.?

The obtained particles were dissolved in $4 \mathrm{ml}$ of $7 \mathrm{M}$

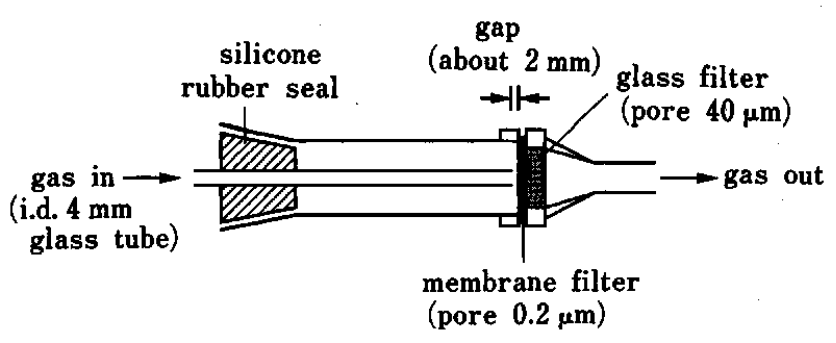

Fig. 1 Schematic diagram of a particle collector. nitric acid and diluted exactly to $25 \mathrm{ml}$ with distilled water. The resulting solution was analyzed by ICPAES or ICP-MS with a series of calibration curves.

\section{Results and Discussion}

The "ablation temperature" seriously affects the magnitude of selective vaporization, which decreases with increasing the temperature. ${ }^{10,14}$ The temperature depends on the types of laser pulses as well as the analyzed material. ${ }^{15}$. Firstly, the effect of the peak power was tested by analyzing the particles obtained with the pulse YAG laser (free-running mode) and the cw Qswitched YAG laser. The results for $\mathrm{Ni}$ and $\mathrm{Mn}$ are shown in Fig. 2. The constant-content ratios of Ni to Fe were obtained for both types of laser pulses, probably due to the similar boiling points of $\mathrm{Ni}$ and $\mathrm{Fe}$. The obtained values agreed with the content ratios of $\mathrm{Ni}$ on the steel standards, especially for the cw Q-switched YAG laser. On the other hand, the peak power has a significant effect on the selective vaporization on $\mathrm{Mn}$ due to the relatively low boiling point of $\mathrm{Mn}$. The use of a lower power led to an increase in the content ratios of $\mathrm{Mn}$ to $\mathrm{Fe}$; constant ratios were obtained at powers greater than $60 \mathrm{~kW}$ and $0.3 \mathrm{MW}$ for the Q-switched $\mathrm{cw}$ YAG and pulse YAG lasers, respectively. The constant values, however, were

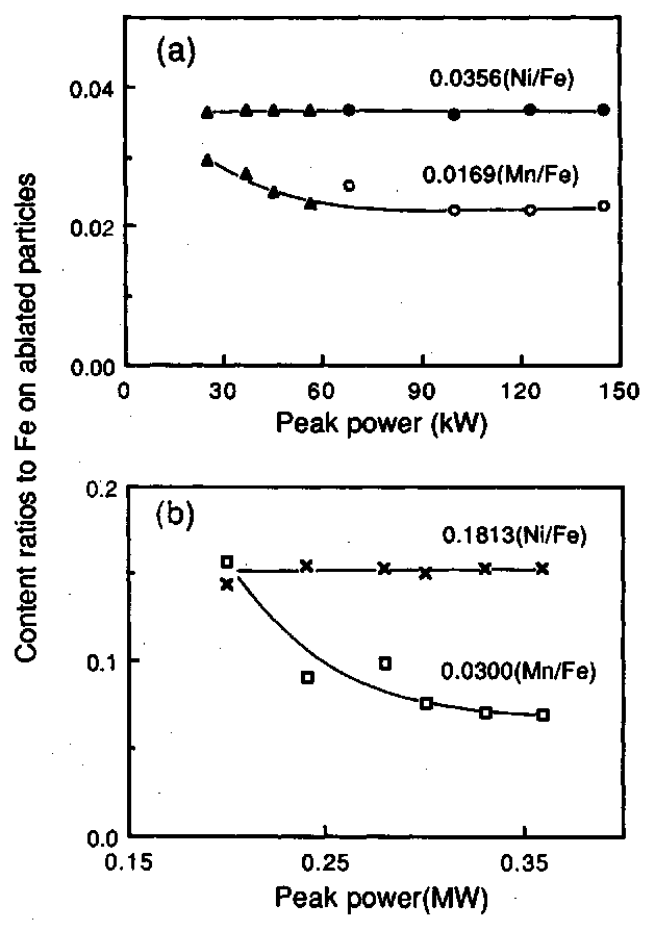

Fig. 2 Effect of the peak power of laser pulses on the selective vaporization of $\mathrm{Mn}$ and $\mathrm{Ni}$. The cw YAG laser shorts were fired at pulse repetition rates of $5 \mathrm{kHz}(\Delta, \Delta)$ and $1 \mathrm{kHz}(O, 0)$ on the JSS151 standard (a). The pulse YAG laser shots in the free-running mode were fired on the JSS652 standard (b). The value on each trace was the content ratio to $\mathrm{Fe}$ on the steel standard. 

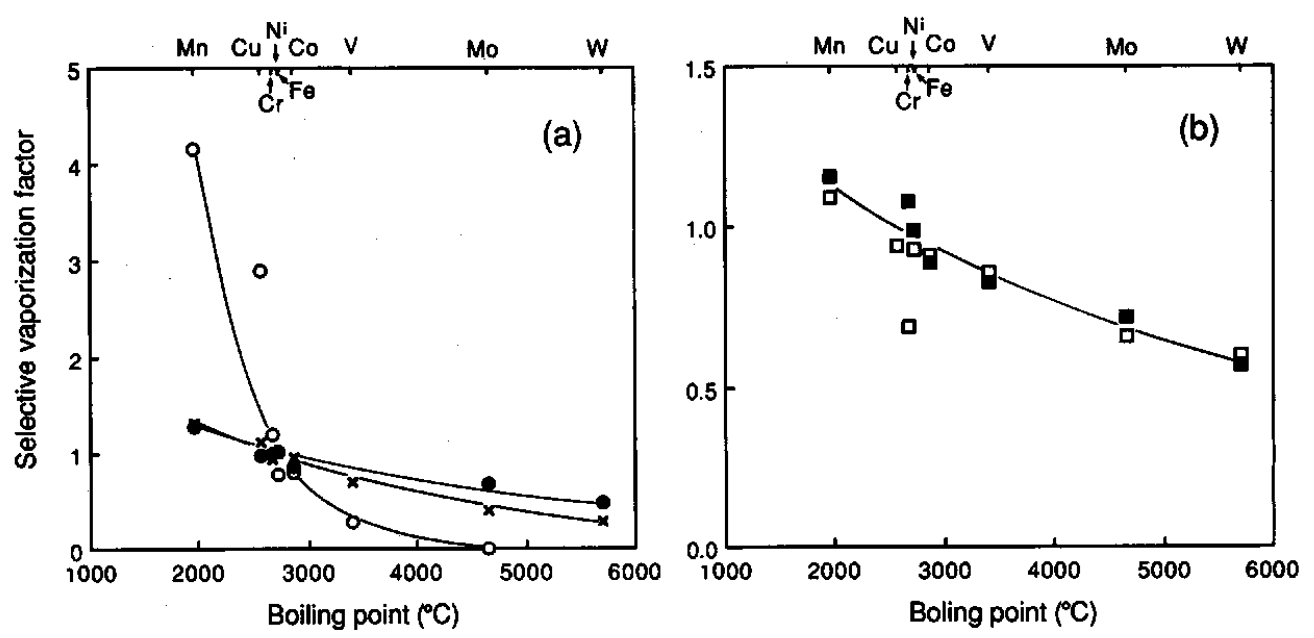

Fig. 3 Selective vaporization factors obtained with the cw YAG and pulse YAG lasers (a) and the ruby laser (b) as the function of boiling points. Laser: pulse YAG with (O) and without $(O)$ Q-switching, Q-switched cw YAG $(X)$, and ruby with lowest $(\square)$ and highest (D) Q-switching. The lasers were operated at the maximum output (see Table 1), except for the $\mathrm{cw}$ YAG laser. The $\mathrm{cw}$ YAG laser was operated at the peak power of $100 \mathrm{~kW}$.

apparently high compared with the ratios on the standards, especially when using the pulse YAG laser in the free-running mode.

The effects of the properties of the laser pulses on selective vaporization were then examined. The selective vaporization factors (SVFs) for five types of laser pulses are compared in Fig. 3. The SVF value of each element was calculated from the slope of a straight line obtained by plotting the content ratios to $\mathrm{Fe}$ on the ablated particles and those on the JSS standards. Elements with a higher boiling point had a lower SVF value for all of the lasers tested. The magnitude of selective vaporization, however, depended on the properties of the laser pulses used. For ablation with the pulse YAG laser, the SVFs obtained under the freerunning mode significantly differed from those obtained under the Q-switching mode. More uniform values were obtained for the Q-switching operation; the values for the free-running operation rather varied from unity: 4.2 for Mn and 0.004 for Mo. These results are the same as those reported by Hager. ${ }^{10}$ Although the magnitude of selective vaporization for the cw YAG laser was low, it was only slightly poor compared with the pulse YAG laser under Q-switching. The SVFs for the ruby laser with the highest and lowest degrees of Q-switching were similar to those for the Q-switched pulse YAG laser. There was no significant difference in the SVFs for the highest and lowest degrees of Q-switching. This result differed from that reported by Thompson et al. ${ }^{13}$, who showed that the effect on the selective vaporization could be minimized by using the highest degree of Q-switching. The reasons for the difference are unclear. The ruby laser with the highest degree of Q-switching could produce a small number of particles, as shown in Table 1 . Therefore, one possibility is an uncertainty of our results regarding the highest degree of $\mathrm{Q}$-switching mode. In conclusion, the degree of selective vaporization could be ordered as follows: Q-switched ruby and pulse YAG laser with Q-switching<cw Q-switched YAG laser< $<$ pulse YAG laser without Q-switching. This ordering indicates that the magnitude of selective vaporization depends on the pulse repetition rate as well as the peak power.

\section{References}

1. R. Wennrich and K. Dittrich, Spectrochim. Acta, 37B, 913 (1982).

2. W. Schron, G. Bombach and P. Beuge, Spectrochim. Acta, 38B, 1269 (1983).

3. R. Wennrich and K. Dittrich, Spectrochim. Acta, 42B, 995 (1987).

4. T. Ishizuka and Y. Uwamino, Anal. Chem., 52, 125 (1980).

5. P. G. Mitchell, J. Sneddon and L. J. Radziemski, Appl. Spectrosc., 41, 141 (1987).

6. T. Ishizuka and Y. Uwamino, Spectrochim. Acta, 38B, 519 (1983).

7. T. Mochizuki, A. Sakashita, T. Akiyoshi and H. Iwata, Anal. Sci., 5, 535 (1989).

8. T. Mochizuki, A. Sakashita, H. Iwata, T. Kagaya, T. Shimamura and P. Blair, Anal. Sci., 4, 403 (1988).

9. P. Arrowsmith, Anal. Chem., 59, 1437 (1987).

10. J. W. Hager, Anal. Chem., 61, 1243 (1989).

11. T. Mochizuki, A. Sakashita, H. Seno and H. Iwata, Bunseki Kagaku, 37, 12 (1988).

12. T. Mochizuki, A. Sakashita and H. Iwata, Bunseki Kagaku, 37, T109 (1988).

13. M. Thompson, S. Chenery and L. Brett, J. Anal. At. Spectrom., 4, 11 (1989).

14. G. I. Ramendik, B. M. Manzon, D. A. Tyurin, N. E. Benyaev and A. A. Komleva, Talanta, 34, 61 (1987).

15. K. Dittrich and R. Wennrich, Prog. Analyt. Atom. Spectrosc., 7, 139 (1984).

(Received January 31, 1991)

(Accepted March 12, 1991) 